\title{
Combined Energy and Process Simulation to Foster Efficiency in Non-automated Material Handling System Design
}

\author{
Patrick Fekete ${ }^{1,2,3}$, Sirirat Lim $^{2}$, Steve Martin ${ }^{1}$, Katja Kuhn ${ }^{3}$, Nick Wright ${ }^{1}$ \\ ${ }^{1}$ Coventry University, Faculty of Engineering and Computing, Coventry, United Kingdom \\ ${ }^{2}$ National Chiao Tung University, Institute of Management of Technology, Hsinchu, Taiwan \\ ${ }^{3}$ SRH University of Applied Sciences, School of Engineering and Architecture, Heidelberg, Germany \\ Correspondence: Patrick Fekete, Coventry University, Faculty of Engineering and Computing, Coventry, United \\ Kingdom.
}

Received: August 10, 2015

doi:10.11114/set.v3i1.1018
Accepted: August 24, 2015 Online Published: December 12, 2015

URL: http://dx.doi.org/10.11114/set.v3i1.1018

\begin{abstract}
Energy and resource efficiency are becoming more and more important objectives in industrial companies, so that it has also become relevant to material handling as part of the lean strategy in supply chain management. The design of sustainable, energy efficient material handling systems and processes depends on methods and tools that analyse and evaluate the composition of the technologies and processes of the system. Therefore analysis on detailed data on energy consumption, energy supply and process organisation is required to improve overall system efficiency. This study proposes a novel approach to energy data generation based on Standardised Energy Consuming Activities (SECA). Simulating process energy consumption and consumption behaviour based on process function investigations increases knowledge about the sequence and characteristics of energy consumption and its process allocation. Executing the research project Usable Battery Energy of the material handling equipment was identified to be gradable by $25 \%$ to $43 \%$ in order to increase equipment availability and thus system efficiency. In the performed case study a system range extension of $19 \%$ to $33 \%$ was reached by the implementation of a fast engaging charging system using process related idle times.

Generally applicable data is required for the design of a scalable simulation to enable the identification of requirements to the design of non-automated material handling system components. The proposed framework forms the basis necessary for the derivation and evaluation of technical and organisational improvement of system efficiency with respect to energy, ecological and economic objectives.
\end{abstract}

Keywords: energy efficiency, process monitoring, energy monitoring, material handling, standardised energy consumption activity

JEL classification: R41, R49, Q41, Q47

\section{Introduction}

In the recent past, global energy demand has exceeded its supply and the International Energy Agency (IEA) forecast predicts this trend to continue at least until 2030 by a further $50 \%$ increase in demand (International Energy Agency, 2014). By this, governments see themselves forced to develop and implement corresponding action plans. As increasing energy production is limited, balancing actions more and more refer to saving energy by developing highly efficient systems and technologies. The industrial and transportation sectors account for almost $37,5 \%$ of the total energy consumption (International Energy Agency, 2014), and have been requested by governmental stimulation to reduce overall energy consumption and to foster their efforts to increase system efficiency.

Driven by these developments, increased public attention as well as rising raw material and energy prices, energy consumption and system efficiency become more and more important aspects especially in product manufacturing where cost of energy accounts for approximately $0.5-3 \%$ of the total turnover (Herrmann \& Thiede, 2009). Existing scientific investigations consider energy consumption and energy efficiency in logistics and material handling majorly in combination with manufacturing and supply chain design in production processes. By this existing research focuses on in-house forwarding from upstream to downstream production processes in the fields of assembly line conveying or 
automated material forwarding. At the point of pure material handling in pre- or post-manufacturing of logistics companies with costs of energy that can account for up to $7 \%$ of the total forwarding cost, energetic considerations are mostly limited to facility design, facility installations or minimising material handling equipment movements in order to decrease energy consumption (Fekete, Martin, Kuhn, \& Wright 2014).

Investigations into material handling focus on delivery and distribution functions based on conventional cost considerations such as energy cost, labour cost and productivity, whereas energy consumption as an indicator for efficiency and processing strategy has rarely been considered (O`Driscoll \& O`Donnell, 2012). Existing research and development focuses on isolated investigations of system and process components targeting increased efficiency of material handling equipment, but neglecting other system or process components and related interdependencies. Specific results might propose optimised solutions for particular process components, rather than the whole process for overall efficiency. Therefore, optimisation of material handling systems has to be based on energy and resource efficiency of all components of a defined system, integrating these into the surrounding process structure (Hopf \& Mueller, 2015). Besides efficiency constraints, major concern in non-automated material handling is equipment availability, so that all developments towards increased efficiency must ensure stable or increased equipment availability as well.

In recent years, increasing attention has been given to battery electric vehicles, especially in the automotive sector. Substantial effort has been made to investigate this technology and its components (Cuma \& Koroglu, 2015). However, most experience in the application of electric vehicles exists in material handling. In 2008, new technical regulations for dangerous goods were introduced in the EU, so that most intra warehouse processes were changed to electric and battery electric industrial trucks and floor conveyors.

In order to understand the interdependencies of all process imminent technologies and functions, fundamental knowledge about all system parameters such as process chain energy consumption, energy supply, process sequences, toolpaths etc. is required in order to investigate the potentials and components to increase overall system and process efficiency (Herrmann \& Thiede, 2009; Kumar, Ray, \& Reed, 2011; O'Driscoll \& O`Donnell, 2012; Balogun \& Mativenga, 2013; Hopf \& Mueller, 2015).

Apart from system development based on isolated technology improvement only, basic understanding of all underlying processes and system components is an essential step to effectively design and manage material handling systems and components. In line with the investigations of Lubik, Lim, Platts, \& Minshall (2012) changing from a technology-push to a market-pull approach based on indeed knowledge of all system components and processes fosters system integration to existing structures and processes and by this overall system efficiency. This paper addresses the gap in literature about the lack of adequately available process and energy data in the field of production related material handling in order to investigate and evaluate the potentials for optimised system design. The aim of this paper is to highlight the applicability of the approach of Standardised Energy Consumption Activities and shows its adequacy to evaluate process and energy optimisation potentials. It does so by examining non-automated material handling energy and process parameters, and their impact on system design, in order to enable

\section{Definition of required energy and process data}

2. Data collection and data generation

3. Deductions to system design

The following section explains the formulation of the framework and method for energy and process data collection based on the literature. This data facilitates the chosen approach of combining energy and process data to deduce requirements for material handling systems and equipment from generally applicable process characteristics. Section 3 explains the underlying core concept of generated data which will also be shown based on a case study. Section 4 summarises results from the case study, and proposes further research work.

\section{Literature Review on Energy and Process Data}

A material handling system is a combination of several repeatedly occurring handling processes with the major function of changing the geographic location of cargo through processing and transportation by using conveying machines, personnel and auxiliary equipment such as charging devices etc.. A process is defined as a sequence of (process) functions. A function is a task that equipment or personnel has to fulfil in order to enable the progress within the supply chain, e.g. lifting or stacking of a pallet. Technical equipment requires energy to process the desired functions. Different functions of a process result in different energy consumption values and consumption profiles. Existing research shows general over-dimensioning of equipment due mainly to inadequate process and energy information (Herrmann \& Thiede, 2009).

Energy Management is a tool for systematically improving energy performance, and can be defined as "forward looking, 
organized and systematic coordination of the procurement, conversion, distribution and utilization of energy in order to cover requirements and which takes ecological and economic objectives into consideration". Energy management also includes organisational (i.e. process) knowledge, technical structures and resources (Association of German Engineers, 2007; Hopf \& Mueller, 2015). The target of energy management is the integration of energy considerations into process operations, enabling the combination of energy and process information in order to increase transparency of energy consumption, supply, wastage and efficiency (Mueller, Poller, Hopf, \& Krones, 2013). Energy management is an essential step in deducing energy and process requirements of non-automated material handling system design.

The energy performance indicators required for energy management can be generated in different ways and are evaluated below.

\subsection{Energy Data}

Energy data can be measured or estimated, but both aim to support energy management with reliable figures in order to determine system energy allocation and to increase system energy performance. The terms Energy Monitoring, Energy Metering and Power Metering can be used synonymously, and are an essential element of Energy Management. As process related energy monitoring needs to be executed at different locations and on different levels, i.e. on process level over different cutting points executed by different forwarding devices that require monitoring adapted to them, special attention must be given to data provision, analysis and visualisation (Pechmann, Hackmann, \& Schöler 2012).

Table 1 shows that most investigations approach energy monitoring by collecting accurate values in order to process them into generalizable figures. Accuracy in most applications is stated to be "as detailed as necessary not as detailed as possible" (Herrmann \& Thiede, 2009). Data collection in most of the investigations serves as basis to enable simulating manufacturing processes, so that precise data is transformed into fixed values in order to process the pursued simulations.

Table 1. Scientific approaches of energy data collection

\begin{tabular}{|c|c|c|}
\hline Author(s) & Data collection strategy & $\begin{array}{c}\text { Energy } \\
\text { calculation }\end{array}$ \\
\hline \multirow{2}{*}{$\begin{array}{l}\text { Herrmann \& } \\
\text { Thiede } 2009\end{array}$} & As detailed as necessary without generating meticulous values. & \multirow{2}{*}{$\begin{array}{c}\text { performance } \\
\text { over time }\end{array}$} \\
\hline & Parameterization enables sensitivity and interdependency analyses. & \\
\hline $\begin{array}{l}\text { Cuma \& } \\
\text { Koroglu } 2015\end{array}$ & Estimation strategy on highly accurate values. & $\begin{array}{c}\text { performance } \\
\text { over time }\end{array}$ \\
\hline Massiani 2015 & Integration of isolated data collection into other sectors. & $\begin{array}{c}\text { consumption } \\
\text { per piece }\end{array}$ \\
\hline $\begin{array}{l}\text { Ahmad \& } \\
\text { Kamaruddin } 2012\end{array}$ & Exact data collection to upkeep realistic results. & $\begin{array}{c}\text { performance } \\
\text { over time }\end{array}$ \\
\hline $\begin{array}{l}\text { O'Driscoll \& } \\
\text { O’Donnell } 2012\end{array}$ & Exact metering. & $\begin{array}{c}\text { performance } \\
\text { over time }\end{array}$ \\
\hline $\begin{array}{l}\text { Balogun \& } \\
\text { Mativenga } 2013\end{array}$ & $\begin{array}{l}\text { Standardised energy data collection based on Basic State and Operating } \\
\text { State. }\end{array}$ & $\begin{array}{c}\text { performance } \\
\text { over time }\end{array}$ \\
\hline $\begin{array}{l}\text { Seow \& } \\
\text { Rahimifard } 2011\end{array}$ & Accurate values. & $\begin{array}{c}\text { performance } \\
\text { over time }\end{array}$ \\
\hline $\begin{array}{l}\text { Hopf \& } \\
\text { Mueller } 2015\end{array}$ & Deduced energy data from engine performance. & $\begin{array}{c}\text { performance } \\
\text { over time }\end{array}$ \\
\hline
\end{tabular}

Investigations of Herrmann \& Thiede (2009), Ahmad \& Kamaruddin (2012), Balogun \& Mativenga (2013) measure current and voltage over time and create the referred load profile from them, so that detailed analyses highlight the load profiles for particular machinery functions.

Massiani refers to the amount of energy being needed to produce one production unit in order to calculate the cost of production.

The dedication of fixed energy in order to execute certain Standardised Energy Consuming Activities (SECA) of production (see section 3) is not executed in any of these investigations. Therefore, major efforts to increase energy efficiency are based on using more efficient technologies and equipment or by implementing energy control applications based on improved energy monitoring (Seow \& Rahimifard, 2011). 


\subsection{Process Data}

Besides energy consumption, research in the field of energy efficiency in manufacturing highlights the importance of energy consumption behaviour based on detailed process knowledge in order to improve system efficiency (Hermann \& Thiede, 2009). Enabled by increased process knowledge, consumption patterns are seen as a key element to defining energy efficient processes and activities (Seow \& Rahimifard, 2011), and thus to analyse and reduce process energy cost (O’Driscoll \& O’Donnell, 2012).

The definition of 'process' in both material handling and in manufacturing covers the material flow from a defined starting point to a defined destination point. However, in contrast to manufacturing, material handling does not include a change of the physical properties of the forwarded goods (Bandow et al., 2013).

Process monitoring in manufacturing can be executed based on different visualisation approaches such as Value Stream Mapping (VSM). Timely predefined production sequences run in the same physical order on predefined material flows, arranged according to Facility or Warehouse Design approaches. Data collection is straightforward, as process functions can be dedicated to specific workstations. Investigating non-automated material handling processes is more complex due to more flexible equipment disposition on timely not predefined sequences.

Research in process monitoring mainly refers to manufacturing processes and referred intra station material handling which mostly runs on predefined routes, using automated handling or fixed conveying devices. Existing research into process investigations of non-automated processes is generally limited to order picking and routing optimisation, with the target to minimise handling times and distances, where process monitoring plays a minor role (DeKoster, Le-Duc, \& Roodbergen, 2006).

Following the postulation of Hopf \& Mueller (2015) for a bounded field of investigation, the monitored processes of this research are restricted to non-automated material handling on industrial trucks with pick-up and delivery and no change of physical properties of goods. Figure 1 shows the simplified material handling process sequence which will be investigated in more detail in this work. In order to increase the information content, process monitoring needs to include information about the process sequence (Weinert, Chiotellis, \& Seliger, 2011; Bandow et al., 2013) as well as physical process allocation and toolpaths, so that process based system design can target increased system efficiency accordingly (Balogun \& Mativenga, 2013).

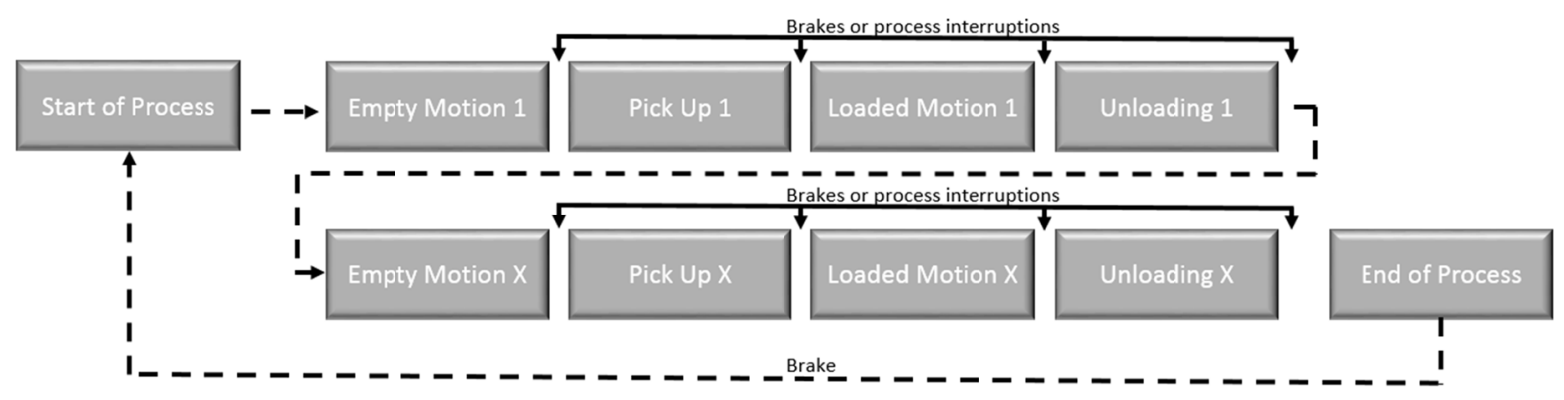

Figure 1. Illustration material handling process

\subsection{Deficits and Potentials}

Several approaches exist to collecting energy and process monitoring data to back up energy management with reliable data. This indicates the general shift of science and industry towards cleaner production, which is recognised to be an integral component of industrial planning, design, operations and management (Klemeš, Varbanov, \& Huisingh, 2012).

Most investigations focus on the development of energy data for a specific process function, with focus on manufacturing processes, so that results are valid but lack general applicability. Hopf \& Mueller (2015), Cuma \& Koroglu (2015) and Massiani (2015) note that existing research lacks combined investigations, so that interdependencies from changing single variables on overall efficiency (Herrmann \& Thiede, 2009) and interdisciplinary observations of associated sectors were not addressed apart from isolated investigations (Massiani 2015).

For battery electric driven systems, case studies suppose energy to be available upon demand. As most non-road electric vehicles of non-automated guidance systems are powered by batteries, practical applications show equipment oversizing in order to ensure a high equipment availability ratio (Herrmann \& Thiede, 2009). In practical applications process energy availability depends on Usable Battery Energy so that process execution can only be granted as long as system batteries have enough energy to power the motors. Research on battery charging infrastructure is concerned with efficiency issues. Process integration and its potentials are neglected, but need to be considered within process and 
energy analysis for system design, as these have an integral impact on the power supply component in system design. Technological developments show battery recharge processes with higher transmission performance as per Figure 2 that can improve equipment availability (Renquist, Dickmann, \& Bradley, 2012).

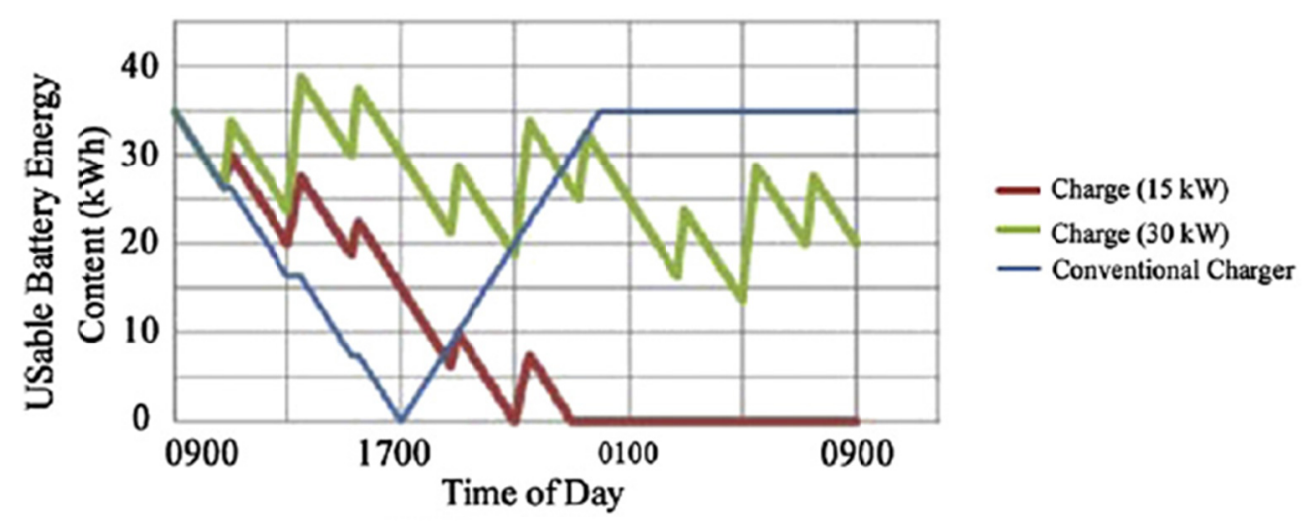

Figure 2. Battery energy content for a workday resulting from three different technologies/charging scenarios; Source:

Renquist et al., 2012

In conclusion, the above analysis highlights the need for generally applicable energy and process data and information in order to optimize overall energy efficiency of non-automated material handling systems. From the combination of both kinds of data, requirements for charging infrastructure as well as material handling equipment can be deduced in respect of energy and material handling process characteristics. The target is to increase overall system efficiency with the given of the defined technical array consisting of material handling equipment, battery charging equipment and intelligent system implementation.

\section{Method}

This research identifies and investigates key performance indicators in non-automated material handling systems. All relevant system components and their inherent variables are included in a comprehensive simulation, so that deductions as to the design of system components can be drawn. In line with Herrmann \& Thiede (2009), besides equipment-related energy and efficiency data, process-based organisational specifications within the material handling system are added to the analysis. Therefore, the research realistically represents the material handling system including the interdependencies and dynamics of all technical equipment involved.

The aim is to operate material handling activities with increased system efficiency through combined process and energy investigations. Besides efficiency constraints, the major concern in non-automated material handling is equipment availability (Ahmad \& Kamaruddin, 2012).

In order to investigate the defined system components in respect of the goals of higher efficiency and availability, relevant key performance indicators have been identified in Figure 3. These serve as the basic structure for the monitoring processes. Data collection provides real data which is used to generate a generally-applicable simulation basis by referring to process based energy modules according to the SECA approach (see chapter 3.1).

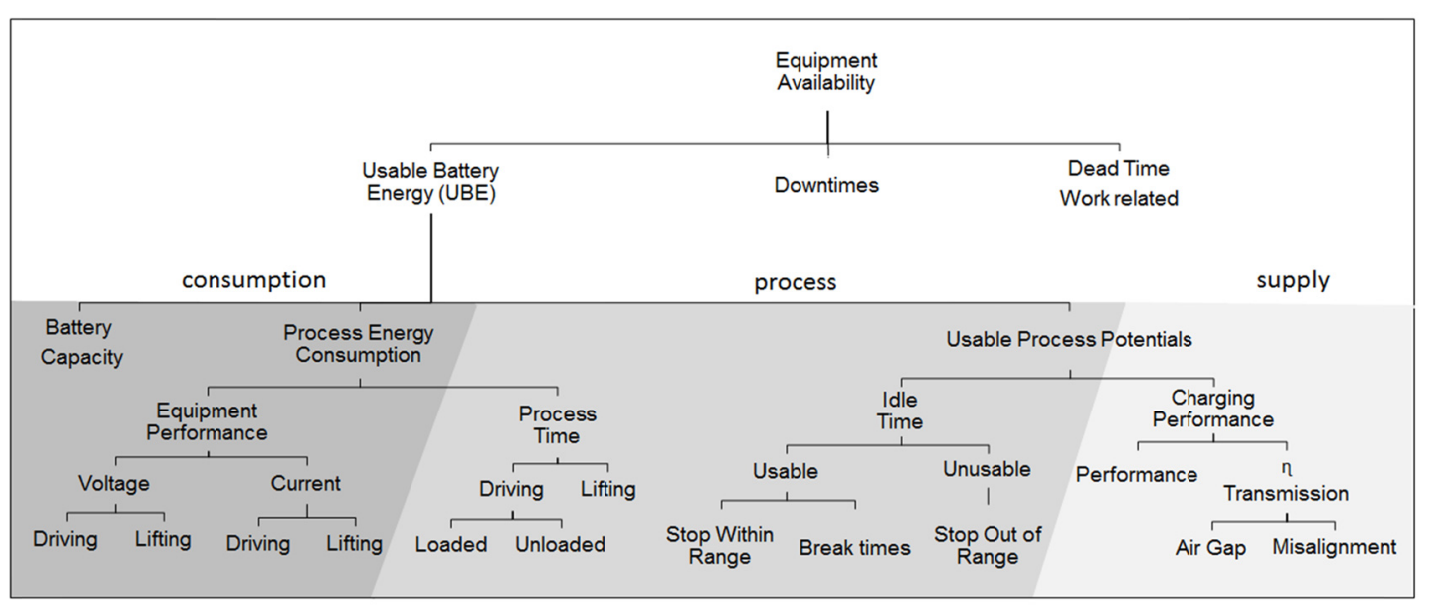

Figure 3. Key performance indicators of equipment availability 
The investigation is structured as a five-step approach, and is shown in Figure 4. The basic data is processed through various steps to generate in-depth information relevant to efficiency in system design (Vijayaraghavan \& Dornfeld, 2010; Rahimifard et al., 2010). Steps 1-3 generate and analyse the required data, giving a reliable and generally applicable basis for further investigation. In step 4, interrelated data is mathematically combined to enable the simulation of process energy consumption and usable process potentials in step 5 .

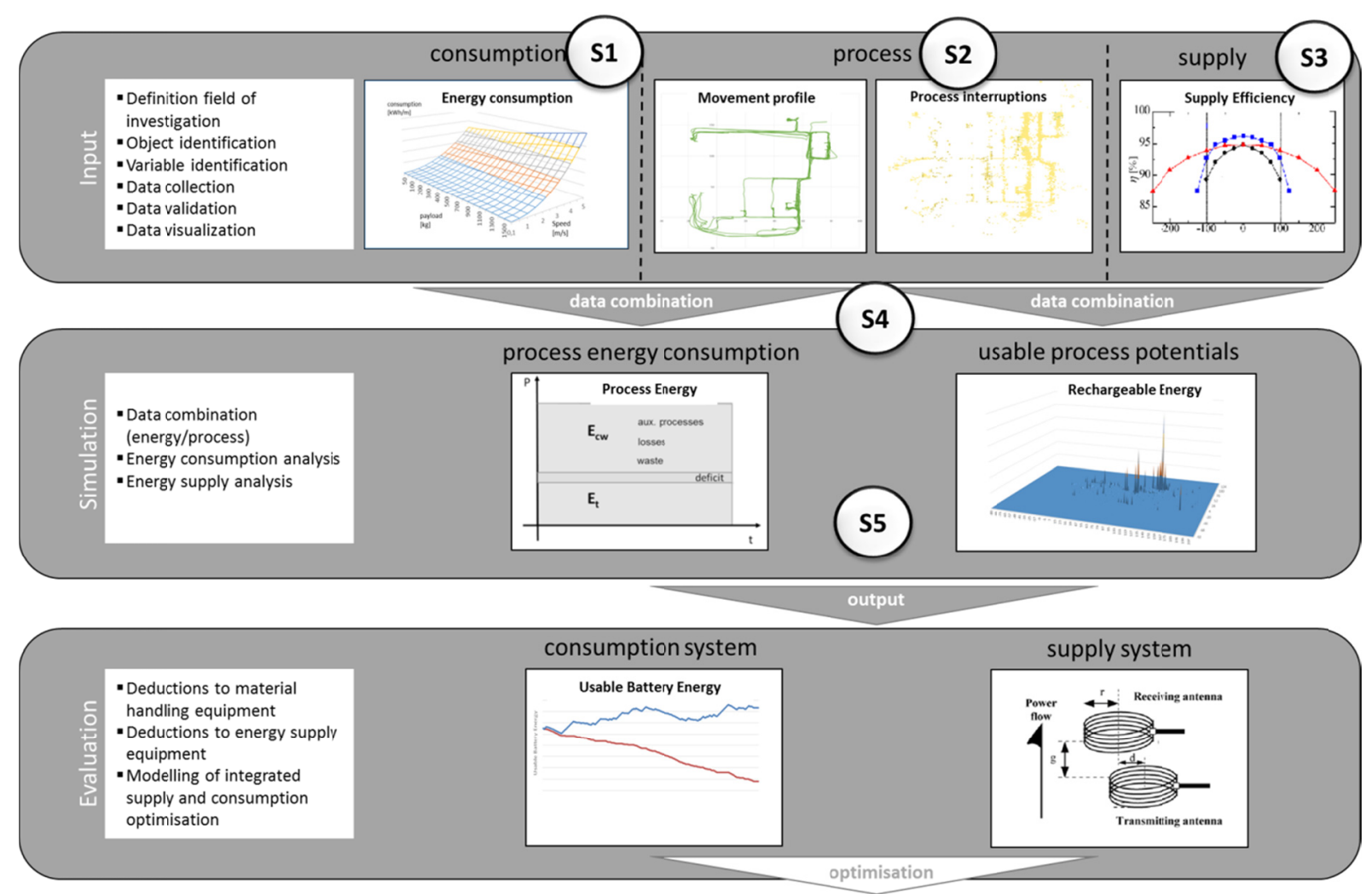

Figure 4. Structured approach to material handling system requirement generation

The systematic approach of Figure 4 ensures the coverage of all defined organisational and energy aspects in order to further optimise existing and developing application systems. The structure of data collection (see chapter $3.1-3.3$ ), data processing and simulation allows the parameterisation of input parameters in order to use sensitivity analyses for more detailed system understanding and investigation of system parameter interdependencies.

\subsection{Step 1-Energy Data Collection \& Analysis}

Energy consumption needs to be measured on a process level, to ensure accurate quantification. As per the approach of Standardised Energy Consuming Activities (SECA), a generalised equipment-level energy model is developed which allows the relating of specific process functions to specific energy usage. Fragmenting a process into its single, repetitively executed functions which each use a certain amount of energy allows simulation of the total process energy demand in correspondence to the results of process monitoring (Fekete et al., 2014).

The generation of SECA is based on the repeated execution of process functions while measuring the energy profile of the handling device. In material handling, typical functions are movement and lifting of goods, so that energy consumption data can be based on lifting a range of weights over a certain height or moving a range of weights over a certain distance (planar handling - see Figure 5 right side). Varying energy consumption due to changing payload caused by diversity of goods must be considered, so that an energy consumption profile as per Figure 4 - step 1 can be defined. 


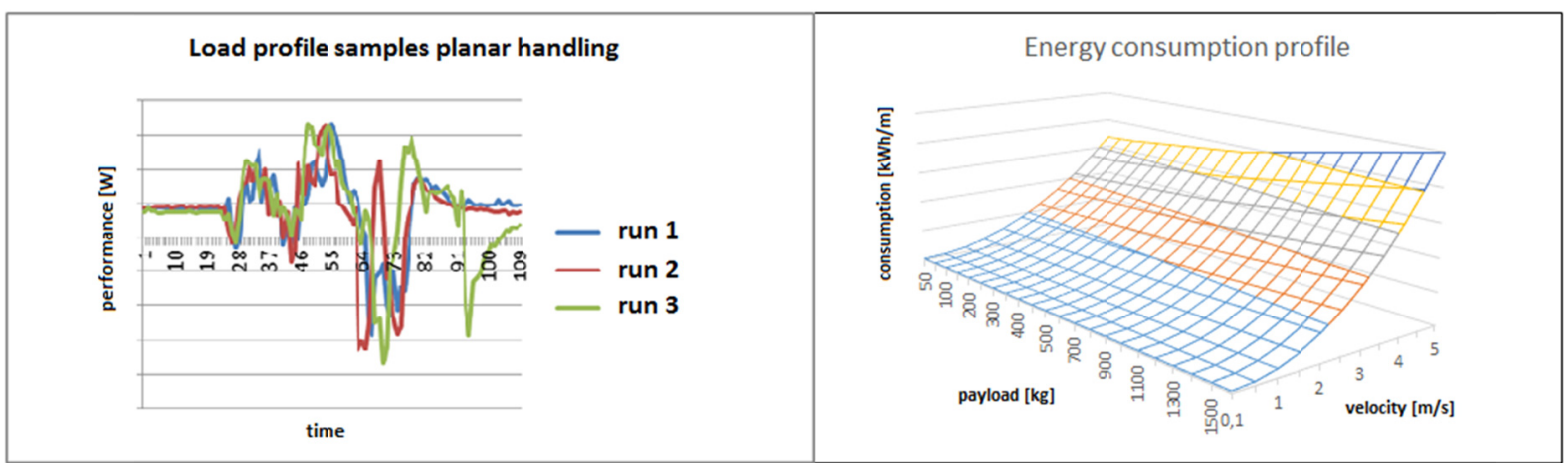

Figure 5. SECA based energy consumption profile development; left: load profile comparison; right: energy consumption profile of planar material handling

Operating SECA over several runs, and gathering average energy consumption and its standard deviation, generates a reliable database. Calculating the ratio of output to input energy gives the function efficiency of the system. Referring to standardised consumption figures based on a broad range of sensitivities enables its usage in multiple applications. Building SECA on basic process functions allows its application to a broad range of applications, while preserving a reasonable precision of energy consumption values within the clearly defined system and process boundaries.

\subsection{Step 2-Process Data Collection}

Within process data collection, all relevant information about technical as well as organisational characteristics of material handling processes needs to be collected in order to gain a deeper understanding of the processes and its sequences. This leads to the generation of a process model which represents the material handling system 's production flows, such as input, output and throughput of packaged items, as well as handled quantities such as number of pieces and average weights.

As per Figure 3, the most important components of process monitoring are processing times, including system operations, auxiliary functions such as empty approaches and departures in order to prepare process operations, and idle times during which equipment is not operating. Idle times may be usable, depending on the existing environmental structure, to recharge vehicle batteries, and thus become system preservation time.

Process monitoring for non-automated processes is more complex than for manufacturing or automated processes which have dedicated, pre-defined routes. As non-automated processes give higher flexibility in terms of equipment-process affiliation, these suit several origin-destination processes based on non-fixed input-throughput-output processes. Process monitoring of non-automated material handling systems shows the main routes within material handling facilities, as well as process interruptions and break time points within the supply chain.

\subsection{Step 3-Environment Investigation}

Investigating the process environment focuses on the surrounding factors that influence the overall system efficiency. Only process related factors with direct impact on the system's energy balance are included, so that energy consumption for heating, illumination, supply of compressed air and other indirect auxiliary functions are not subject of the investigations.

Besides the arrangement of material handling facilities and its impact on the installation of energy supply equipment, the focus of environmental investigations is set on the possible positioning of process integrated energy supply systems. This is influenced by the supply system characteristics such as transmission performance and transmission efficiency, and the resulting supply system technical restrictions and requirements.

\subsection{Step 4-Data Combination}

The combination of energy consumption data, based on SECA steps, and process data allows identification of process and consumption drivers, and by this the analysis of specific process energy consumption. Figure 6 shows how SECA blocks, representing a certain amount of energy being necessary to execute relevant process steps, become defragmented, and thus highlight energy consumption behaviour and characteristics of investigated processes. The criteria for the energy consumption classification are based on the research environment and the level of energy consumption of operating material handling equipment. The categorisation into high energy consumption serves as a first hint on the further optimisation of process steps and functions in order to decrease system energy consumption. In reference to the overall system energy consumption of individual functions, also low energy consuming functions are target to further improvement which can easily be identified based on the defragmentation process. 


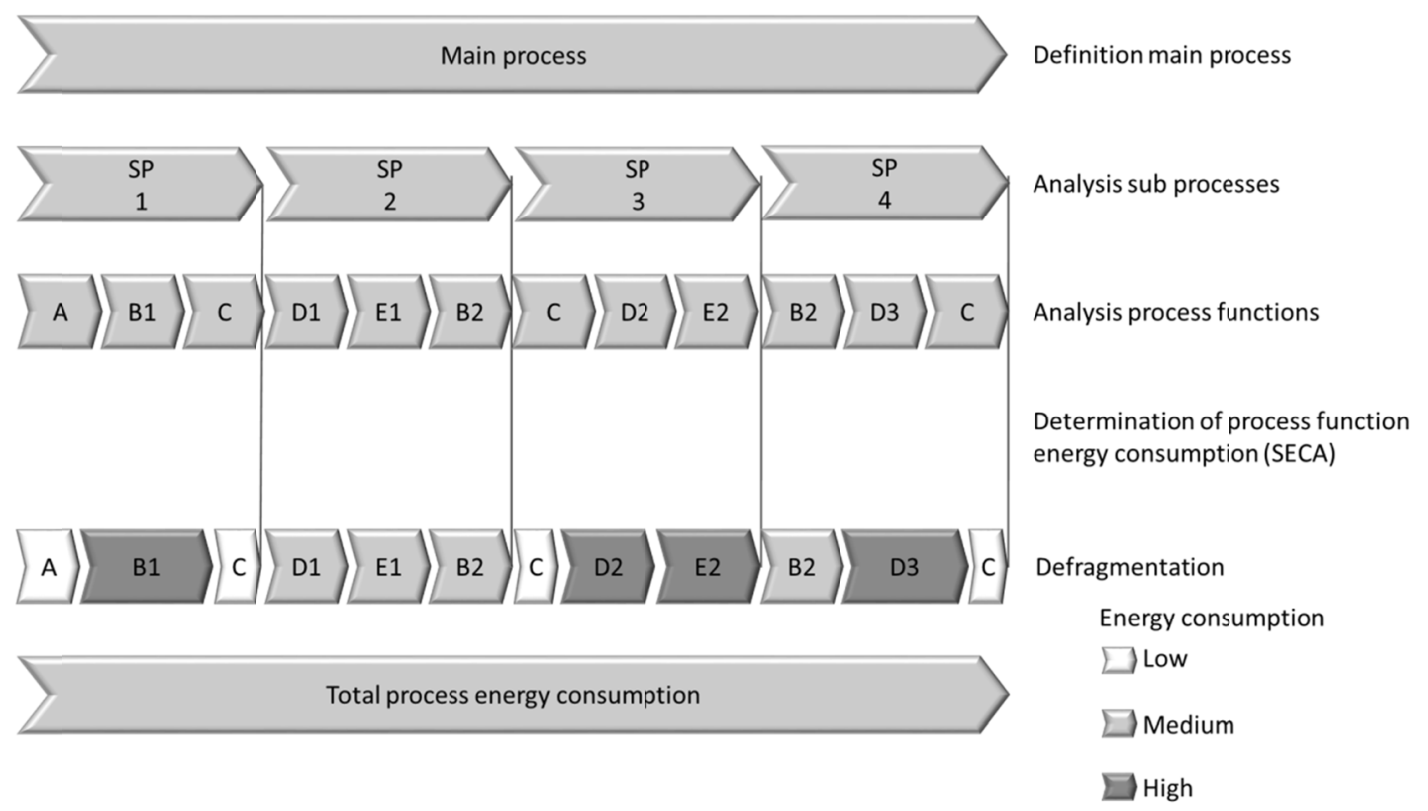

Figure 6. Process energy investigation using SECA

The combination of process interruptions due to process characteristics in combination with information deduced from the system`s environment such as installation requirements as well as technical performance completes the basis to generate more detailed information on system energy supply potentials.

\subsection{Step 5-Integrated Simulation}

In order to analyse interdependencies between technical and process based production variables and system design, as well as the results of any organisational restructuring and/or technical development, the whole process chain within the defined boundaries including the system`s overall energy balance needs to be investigated.

Simulation at this stage focuses on the requirements of material handling system design, and includes all relevant energy consumption data, material handling equipment toolpaths and energy supply information in order to cope with the dynamics of the system. Increasing equipment availability as well as system efficiency based on a minimum level of resources has to be implemented with minimal impact on the core functions of the system.

In its initial stage, simulations are performed in an easy-to-adapt and easy-to-use, Excel based application. The mathematical foundation is based on a case-adapted Maximal Covering Location Problem algorithm which stepwise integrates energy and process data into the determination of charging infrastructure allocation. The drafted approach allows the investigation of occasional recharging to the system energy balance.

Simulating technical and process characteristics of the system, and sensitivity analyses based on parameterisation, enable the deduction of requirements for individual system components, as well as the impact to the overall system energy balance, so that in a further analysis technical adaptions to the defined requirements necessitate further development and investigation.

\section{Application and Discussion}

The approach described above, of investigating energy and process characteristics and their impact on system design of material handling processes, is applied to a practical case in order to highlight potential and actual applicability. The case investigations focus on material handling in a car production environment. Major functions of investigated handling equipment refer to the supply of assembly lines with spare parts and component parts as well as outlet belt evacuation by forwarding of manufactured goods to subsequent distribution channels. The primary production line function is a high output generation. The investigated processes are accounted as auxiliary functions. High efficiency under minimal resource consumption and increased equipment availability characterise this kind of production approach. The system sensitivity to process breakdowns and supply shortages require cost efficient and reliable auxiliary processes so that investigating the integration of an occasional recharging infrastructure is considered to contribute to increased process stability by equipment availability as well as overall efficiency.

The production facility investigated consists of six production lines which are supplied with parts that are arranged within pallet cage boxes with a tare of $85 \mathrm{~kg}$ each. Loaded boxes range from $100 \mathrm{~kg}$ to $700 \mathrm{~kg}$. Process monitoring showed that the average velocity of the industrial trucks ranged from $1,9 \mathrm{~km} / \mathrm{h}$ up to $2,6 \mathrm{~km} / \mathrm{h}$. The related energy 
consumption values for planar handling were calculated and are shown in Figure 7. Pallets are not stacked, so energy demand for lifting is limited to the free lift of the loading device.

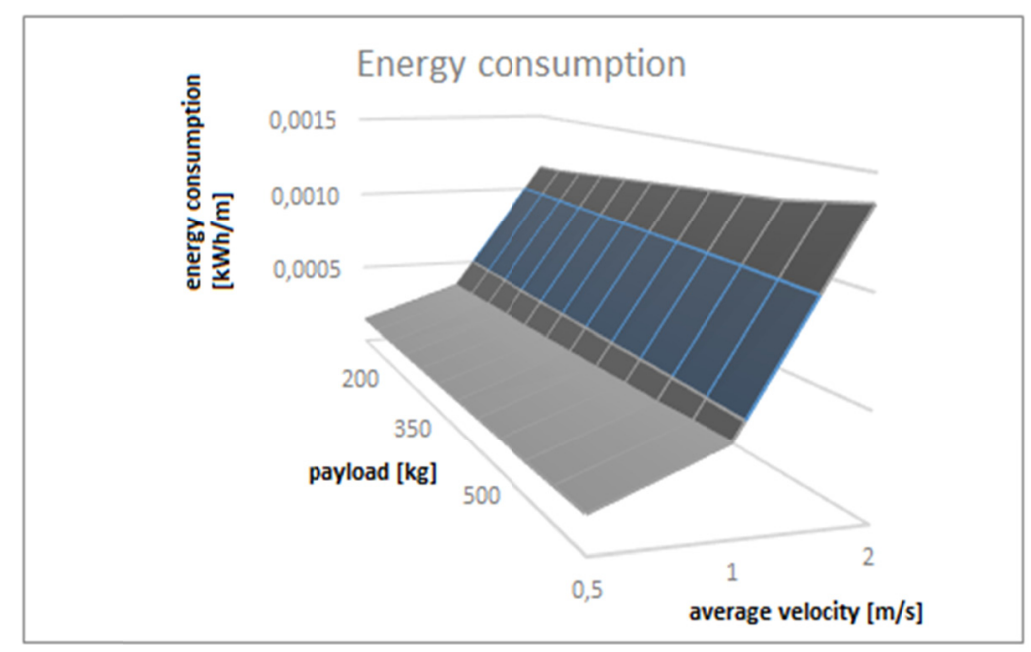

Figure 7. Energy consumption for planar handling

The supply of all six production lines uses six industrial trucks of the same model. Their monitored operating routes are displayed in Figure 8, and the differences and overlaps between these routes can be seen.

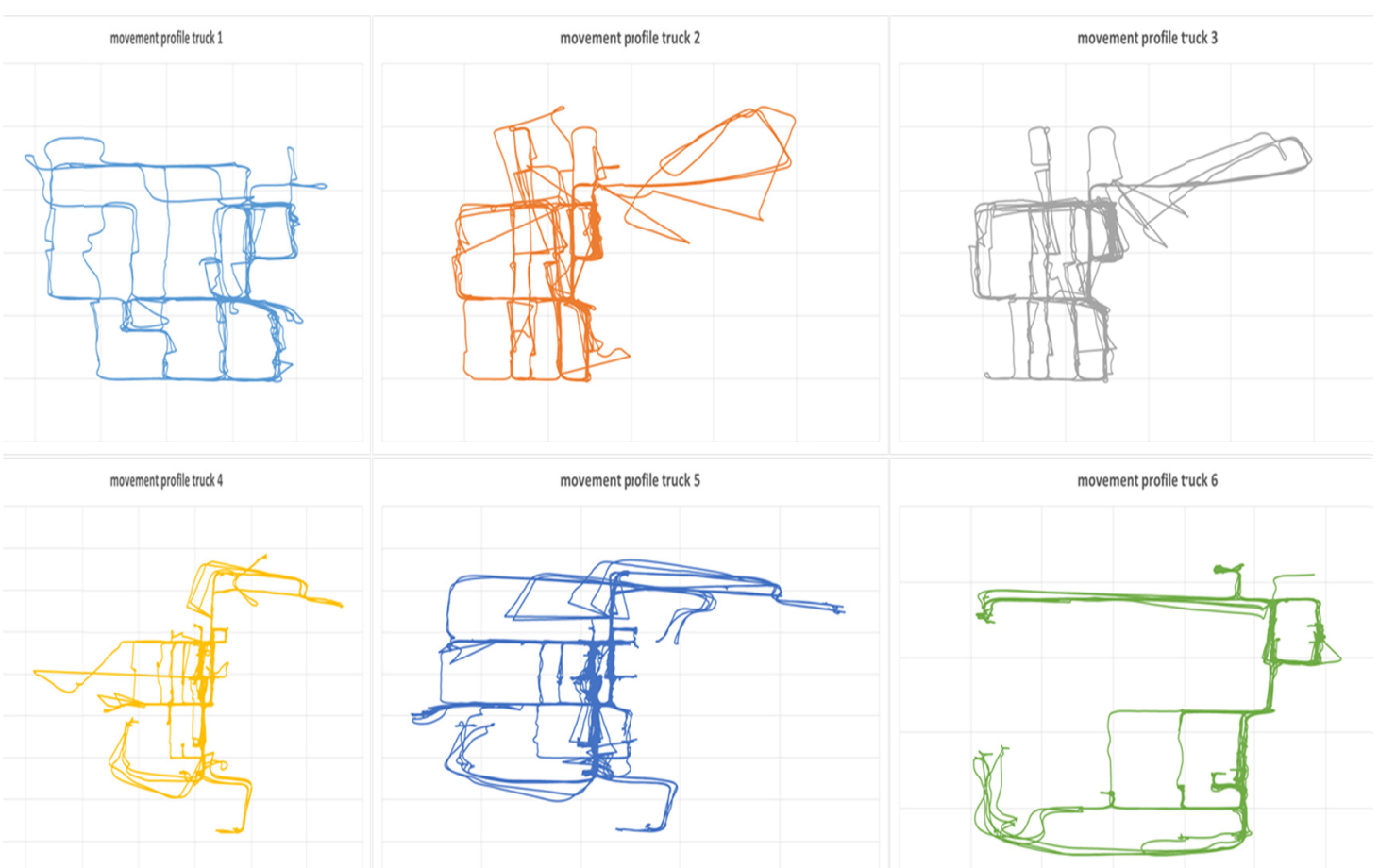

Figure 8. Material handling operation profiles

The locations of process interruptions such as process related waiting times, unforeseen waiting times and preparation times for pick up and unloading were identified, and are shown in table 2 . These account for up to $21 \%$ of the total operating hours of the material handling system. A general break time of one hour between two shifts with the truck location remaining constant is not included within this value.

These process interruptions can be divided between process-specific interruptions (ones that are seen as part of the process, and thus regularly occur in the same location) and non-specific interruptions that occur due to other processes that stop material handling equipment. The latter can be differentiated further into regular and random occurrences. Random occurrences appear irregularly and in different locations, and are not predictable due to the flexibility of the system arrangement. Regularly occurring interruptions are located in facility areas where several processes cross, and at port locations on the system boundaries. 
Table 2. Occurrence of process interruptions on shift basis

\begin{tabular}{lclll}
\hline Typical duration & Process specific & Occurrence & Other specifications & Fraction \\
\hline $1-10 \mathrm{sec}$ & No & Frequent & $\begin{array}{l}\text { In front of crossings, } \\
\text { intersections, gateways }\end{array}$ & $20.6 \%$ \\
$1-25 \mathrm{sec}$ & No & Non-frequent & $\begin{array}{l}\text { Random distribution } \\
\text { within facility }\end{array}$ & \\
\hline $10-180 \mathrm{sec}$ & Yes & Frequent & $\begin{array}{l}\text { In front of pick-up and } \\
\text { delivery zones }\end{array}$ & $49.6 \%$ \\
& & \multicolumn{2}{l}{$\begin{array}{l}\text { Include process } \\
\text { preparation/execution }\end{array}$} & \\
\hline $10-60 \mathrm{~min}$ & No & Frequent & Break time & $29.8 \%$ \\
\hline
\end{tabular}

Idle times which show a regular occurrence in constant locations can be used to increase the amount of Usable Battery Energy of the material handling equipment such as industrial trucks, order pickers, etc. by $25 \%$ to $43 \%$ in order to increase equipment availability and thus system efficiency. In the executed case study, this leads to a system range extension of $19 \%$ to $33 \%$.

Considering the energy input-to-output ratio, increasing the output with no corresponding increase of the input will increase process efficiency, but requires the isolated investigation of individual system components so that decreasing energy consumption of handling equipment or increasing energy transmission efficiency contribute to increased overall system efficiency. The focus of this investigation is to deduce requirements for the whole set of system components based on the process characteristics. In order to use frequently occurring process idle time, several implications for system design can be deduced:

Table 3. Implications to material handling system design

\begin{tabular}{lll}
\hline Specification & material handling equipment & energy supply infrastructure \\
\hline $\begin{array}{l}\text { Usage of short } \\
\text { break times }\end{array}$ & Fast and easy connection & Fast and easy connection \\
$\begin{array}{l}\text { Loss reduction } \\
\text { Transmission } \\
\text { energy }\end{array}$ & High storage efficiency & High energy storage performance \\
maximisation & & $\begin{array}{l}\text { High energy transmission performance } \\
\text { (fast charging application) }\end{array}$ \\
$\begin{array}{l}\text { Process } \\
\text { integration }\end{array}$ & Precise handling features & $\begin{array}{l}\text { Non-disturbing implementation } \\
\text { Flexible installation }\end{array}$ \\
\hline
\end{tabular}

As per the above explanations powering of processes can be supported by a flexible and fast engaging power supply system. By this, $31,87 \%$ to $52,21 \%$ of the total usable break times can be used for recharging the battery. This allows to increase the Usable Battery Energy for another $17 \%$ to $27 \%$ of the daily energy consumption. Allocation of recharging infrastructure needs to be analysed thoroughly in order to facilitate a high use rate, for example in process overlap areas of material handling. In accordance with the above mentioned process characteristics, fast plug-in or wireless power transfer solutions need to be investigated more precisely in order to evaluate their applicability to existing process structures and environments. Therefore further simulations on infrastructure allocation will have to highlight the impact of system allocation to system energy balance in order to investigate the potentials for system optimization.

\section{Conclusion}

In order to tackle climate and energy challenges, companies that are influenced by material handling, and especially logistics providers, are forced to improve energy efficiency within their systems. The integration of academic results to practical application is as essential step to increase process and consumption knowledge in order to provide meaningful data for system optimisation. This paper highlights the requirements for system design that emerge from process and energy monitoring. It can be concluded that improvement of single components contributes to increased overall efficiency, but is not sufficient on its own in terms of a comprehensive efficiency approach. In contrast to most scientific investigations on isolated process or system components, this combined model enables the evaluation of interdependent impacts from system changes. The results of this study highlight fields for further system improvements and the expectable dimension of impact of different approaches to overall efficiency.

Potential improvements have been highlighted by investigating the complete system including consumption, supply and process organisation. In order to further improve energy efficiency in this field, system simulations included intelligent 
allocation of energy supply infrastructure based on the defined, monitored and processed data. Deriving favourable measures to optimise system composition depends on the constitution of an appropriate simulation and evaluation approach.

Therefore parameterisation in simulating energy based system composition will enable the determination of main drivers in respect to technical, ecological and economic improvement. The executed five-step approach based on the monitoring of process and energy data in reference to the SECA approach enables a general applicability to similar process functions of different processes based on a reliable data base. The conducted case study highlights the potentials of the executed investigation, as well as the need for further investigation in the fields of system allocation, system composition, and the identification of system variable interdependencies in order to enable increased overall efficiency.

Energy and process data was transferred to average numbers, so that the executed simulations focus on the evaluation of total energy consumption and potentials for integrating an occasional energy recharging infrastructure. Therefore, these simulations don't provide information about peak loads and maximum material stress which also need to be considered for technical system design.

Future research has to increase the number of SECA and process data applications in adjacent areas of material handling in order to enlarge the available data basis for process and energy studies and by this enable complete system energy investigations. In further research studies, the approach of improving system energy efficiency by integrating energy transfer systems for occasional recharging needs further technical examination. Due to the general applicable design of the executed approach it can be used for further investigations in related production environments.

\section{References}

Ahmad, R., \& Kamaruddin, S. (2012). An overview of time-based and condition-based maintenance in industrial application. Computers and Industrial Engineering, 63(2012), 135-149. http://dx.doi.org/10.1016/j.cie.2012.02.002

Balogun, V. A., \& Mativenga, P. T. (2013). Modelling of direct energy requirements in mechanical machining processes. Journal of Cleaner Production, 41(2013), 179-186. http://dx.doi.org/10.1016/j.jclepro.2012.10.015

Bandow, G., Woetzel, A., \& Man, K. Y. (2013). Performance measurement system for efficiency of intralogistics-systems. International Conference on Competitive Manufacturing. 30 January - 01 February 2013, Stellenbosch, South Africa.

Cuma, M. U., \& Koroglu, T. (2015). A comprehensive review on estimation strategies used in hybrid and battery electric vehicles. Renewable and Sustainable Energy Reviews, 42(2015), 517-531. http://dx.doi.org/10.1016/j.rser.2014.10.047

DeKoster, R., Le-Duc, T., \& Roodbergen, K. J. (2006). Design and control of warehouse order picking: a literature review. European Journal of Operational Research, 182(2), 481-501.

Fekete, P., Martin, S., Kuhn, K., \& Wright, N. (2014). The status of energy monitoring in science and industry by the example of material handling processes. Business, Management and Education, 12(2), 213-227. http://dx.doi.org/10.3846/bme.2014.23

Herrmann, C., \& Thiede, S. (2009) Process chain simulation to foster energy efficiency in manufacturing. CIRP Journal of Manufacturing Science and Technology, 1(2009), 221-229. http://dx.doi.org/10.1016/j.cirpj.2009.06.005

Hopf, H., \& Mueller, E. (2015). Providing energy data and information for sustainable manufacturing systems by Energy Cards. Robotics and Computer-Integrated Manufacturing. http://dx.doi.org/10.1016/j.rcim.2014.12.006

International Energy Agency (2014). Key World Energy Statistics. Paris: International Energy Agency.

Klemeš, J. J., Varbanov, P. S., \& Huisingh, D. (2012). Recent cleaner production advances in process monitoring and optimisation. Journal of Cleaner Production, 34(2012), 1-8. http://dx.doi.org/10.1016/j.jclepro.2012.04.026

Kumar, R., Ray, P. D., \& Reed, C. (2011). Smart Grid: An Electricity Market Perspective. IEEE PES Innovative Smart Grid Technologies (ISGT 2011), Piscataway, NJ, USA, p. 8. http://dx.doi.org/10.1109/ISGT.2011.5759184

Lubik, S., Lim, S., Platts, K., \& Minshall, T. (2012). Market-pull and technology-push in manufacturing start-ups in emerging industries. Journal of Manufacturing Technology Management, 24(2012), 10-27. http://dx.doi.org/10.1108/17410381311287463

Massiani, J. (2015). Cost-Benefit analysis of policies for the development of electric vehicles in Germany: Methods and results, Transport Policy, 38(2015), 19-26. http://dx.doi.org/10.1016/j.tranpol.2014.10.005

Mueller, E., Poller, R., Hopf, H., \& Krones, M. (2013). Enabling energy management for planning energy-efficient factories, Proc. CIRP 7(2013), 622-627. http://dx.doi.org/10.1016/j.procir.2013.06.043 
O`Driscoll, E., \& O`Donnell, G. E. (2012). Industrial power and energy metering - a state-of-the-art review. Journal of Cleaner Production, 41(2013), 53-64. http://dx.doi.org/10.1016/j.jclepro.2012.09.046

Pechmann, A., Hackmann, R., \& Schöler, I. (2012). Measuring and visualizing different energy sources - a concept for an energy management system, in: Proceedings of the 19th CIRP Conference on Life Cycle Engineering, University of California at Berkeley, Berkeley, USA, 2012, pp. 527-533.

Rahimifard, S., Seow, Y., \& Childs, T. (2010). Minimising embodied product energy to support energy efficient manufacturing. CIRP Annals - Manufacturing Technology, 59(201), 25-28. http://dx.doi.org/10.1016/j.cirp.2010.03.048

Renquist, J. V., Dickmann, B., \& Bradley, T. H. (2012). Economic comparison of fuel cell powered forklifts to battery powered forklifts. International Journal of Hydrogen Energy, 37(2012), 12054-12059. http://dx.doi.org/10.1016/j.ijhydene.2012.06.070

Seow, Y., \& Rahimifard, S. (2011). A framework for modelling energy consumption within manufacturing systems. CIRP Journal of Manufacturing Science and Technology, 4(2011), 259-264. http://dx.doi.org/10.1016/j.cirpj.2011.03.007

Vijayaraghavan, A., \& Dornfeld, D. (2010). Automated energy monitoring of machine tools. CIRP Annals Manufacturing Technology, 59(2010), 21-24. http://dx.doi.org/10.1016/j.cirp.2010.03.042

Weinert, N., Chiotellis, S., \& Seliger, G. (2011). Methodology for planning and operating energy-efficient production systems. CIRP Annals - Manufacturing Technology, 60(2011), 41-44. http://dx.doi.org/10.1016/j.cirp.2011.03.015

\section{$(\mathrm{cc}) \mathrm{EY}$}

This work is licensed under a Creative Commons Attribution 3.0 License. 